\title{
Recent Advances in QEPAS and QEPTS Based Trace Gas Sensing: A Review
}

\author{
Yufei Ma* \\ National Key Laboratory of Science and Technology on Tunable Laser, Harbin Institute of Technology, Harbin, China
}

This invited review paper summarizes and discusses developments of QTF based state-of-the-art quartz-enhanced photoacoustic spectroscopy (QEPAS) and quartz-enhanced photothermal spectroscopy (QEPTS) gas sensing techniques over the past 3 years. Due to the merits of a high quality factor, a narrow resonance frequency band, a low cost, a small volume, and immunity to the laser wavelength, a QTF is widely used as a sensitive detector in sensing photoacoustic spectroscopy and photothermal spectroscopy based gas. The review also presents prospects in the development of QEPAS and QEPTS based gas sensing techniques.

\section{OPEN ACCESS}

Edited by:

Petra Granitzer,

University of Graz, Austria

Reviewed by:

Jianming Wen

Kennesaw State University,

United States

Lei Dong,

Shanxi University, China

${ }^{*}$ Correspondence:

Yufei Ma

mayufei@hit.edu.cn

Specialty section:

This article was submitted to

Optics and Photonics,

a section of the journal

Frontiers in Physics

Received: 25 March 2020

Accepted: 16 June 2020

Published: 31 August 2020

Citation:

Ma Y (2020) Recent Advances in QEPAS and QEPTS Based Trace Gas Sensing: A Review.

Front. Phys. 8:268.

doi: 10.3389/fphy.2020.00268
Keywords: trace gas sensing, quartz tuning fork, laser spectroscopy, QEPAS, QEPTS

\section{INTRODUCTION}

Due to the advantages of high selectivity and sensitivity, cost benefits, in-situ and non-invasiveness detection [1-3], optical gas sensors are widely used in numerous fields, such as combustion diagnostics, atmospheric monitoring, life sciences, planetary exploration, environmental monitoring, and early fire detection [4-9]. Many laser spectroscopy-based methods such as tunable diode laser absorption spectroscopy (TDLAS) [10-15], photoacoustic spectroscopy [16-18], and photothermal spectroscopy [19] have been adopted extensively.

Quartz tuning fork (QTF) is an element made from silicon dioxide $\left(\mathrm{SiO}_{2}\right)$ that has a piezoelectric effect. A QTF is fabricated by photolithographic and chemical etching techniques [20]. It is widely used to produce the clock rate in electronic circuits, crystal watches, and timers. Due to its high quality factor $(\sim 100,000$ in vacuum, $\sim 10,000$ at normal atmospheric pressure) and a narrow resonance frequency band $(<1 \mathrm{~Hz})$, a QTF is widely used as a sensitive detector in many fields, such as atomic force microscopy, scanning near-field optical microscope, Femto-Newtonian force sensing, alternating gradient magnetometer, magnetic force microscopy, and detection of electric field intensity distribution [21-26].

With a U-pattern geometry, a QTF is formed from two fork prongs. The unique acoustic quadrupole structure and narrow resonance frequency band of a QTF mean that it has excellent immunity to environment noise [27-29], which is advantageous in reducing the system noise level and therefore improves the signal to noise ratio (SNR) of a QTF-based gas sensor. Furthermore, compared to an optical detector used in TDLAS, especially an expensive mercury cadmium telluride (MCT) detector with cryogenic cooling, a QTF is less costly $(<\$ 1)$ and immune to the laser wavelength [30-33]. Furthermore, the small size of a QTF is beneficial to reducing a sensor's volume. Due to the advantages mentioned above, a QTF is widely used as a detector in photoacoustic spectroscopy and photothermal spectroscopy based gas sensing [34-37]. 


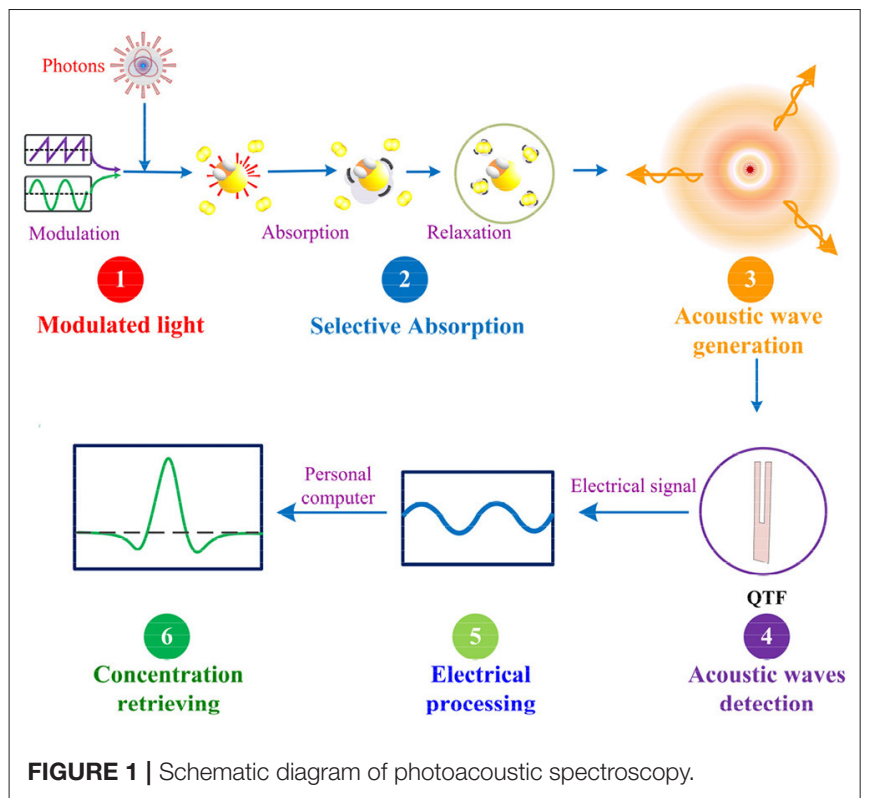

\section{QUARTZ-ENHANCED PHOTOACOUSTIC SPECTROSCOPY (QEPAS) BASED GAS SENSING}

Photoacoustic spectroscopy is a sensitive trace gas detection method. When the output of a light source (laser, LED, etc.) is absorbed by a gas sample due to non-radiative processes, the absorbed optical energy is transformed into heat energy. This process increases the localized temperature and pressure in the gas sample. If the intensity of the light is modulated, an acoustic wave will be generated $[38,39]$. The intensity of the generated acoustic wave relates to the sample concentration and therefore can be used to retrieve the gas concentration. The acoustic wave can be detected by a sensitive acoustic wave transducer, such as a microphone, a cantilever, or a QTF [40-42]. A schematic diagram of photoacoustic spectroscopy is shown in Figure 1. Photoacoustic spectroscopy is regarded as an advanced technique for gas sensing, which offers several merits such as compact size, a wide dynamic range, non-destructive detection, and simplicity in the setup [43].

Quartz-enhanced photoacoustic spectroscopy (QEPAS) was first reported in 2002 by Tittel [44]. In QEPAS, a QTF is used to detect an acoustic wave. The laser beam passes through the gap between the two prongs of QTF and excites the gas molecules [45-49]. Figure 2 shows the schematic diagram of the laser beam, a QTF, and the produced acoustic wave. A QEPAS sensor has the merits of high sensitivity (ppt-ppm level), compactness, low cost, and a large dynamic range [50-58]. As a result, it has been widely adopted in the detection of numerous gases for biomedical diagnostics [59-61], chemical analysis [62-65], atmospheric monitoring [66-73], and trace gas sensing [7481]. Different types of QEPAS sensors have been developed in recent years to meet the requirements of (1) a robust structure, (2) an ultra-high sensitivity, and (3) a distributed gas sensing

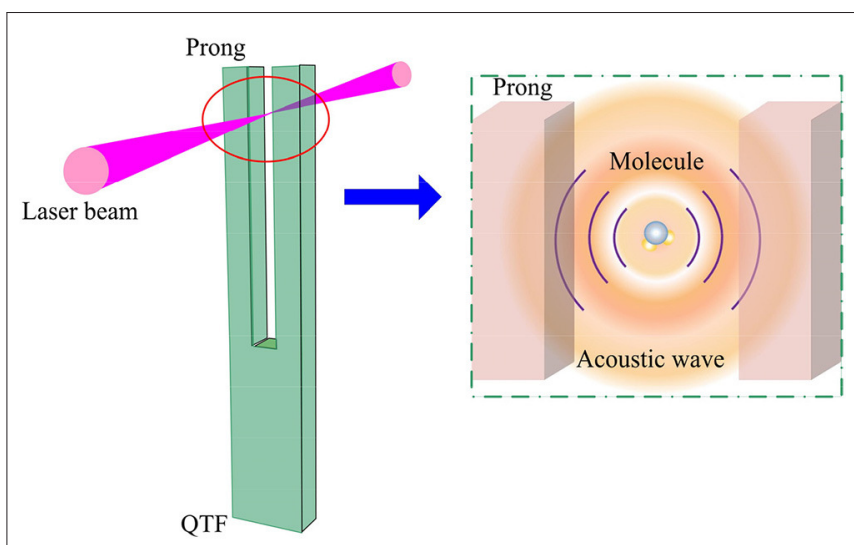

FIGURE 2 | Schematic diagram of a QTF, a laser and an acoustic wave in a QEPAS sensor.

ability. This review discusses these issues of interest in section Quartz-Enhanced Photoacoustic Spectroscopy (QEPAS) Based Gas Sensing.

\section{Mid-Infrared All-Fiber QEPAS Sensor With a 3D-Printed ADM}

A 3D printing technique was introduced as it has the advantages of high stability and integration, which provides an easy way of fabricating sensors as well as implementing sensor applications that require compact size and lighter weight. In 2018, we used a 3D printing technique to fabricate a compact acoustic detection module (ADM) for a QEPAS sensor [82]. With a size of $29 \times 15$ $\times 8 \mathrm{~mm}^{3}$, the design model is shown in Figure 3a.

Compared with separate optical elements, an all-fiber configuration has the merits of lower insertion loss, easier optical alignment, improved system stability, reduction in sensor size, and a lower cost. A mid-infrared fiber-coupled Grin lens using an ion exchange method was fabricated in 2019 [83]. The Grin lens was used for laser coupling in a mid-infrared all-fiber carbon monoxide (CO) QEPAS sensor, employing a diode laser with an emission wavelength of $2.3 \mu \mathrm{m}$. The mid-infrared all-fiber structure combined with a 3D-printed ADM further improved the stability of the system and reduced the volume and weight of the sensor. A UV-curable resin was used as the processing material. Finally, a sensor mass of $\sim 5 \mathrm{~g}$ was obtained for the $3 \mathrm{D}$ printed ADM with a mid-infrared all-fiber structure, shown in Figures 3b, c.

An Allan deviation analysis was performed to evaluate the long-term system stability of the mid-infrared all-fiber $\mathrm{CO}$ QEPAS sensor with a 3D-printed ADM. A minimum detection limit (MDL) of $1.3 \mathrm{ppm}$ was observed when the integration time was $150 \mathrm{~s}$. Long-term system drifts start to dominate after an integration time of $150 \mathrm{~s}$, which demonstrated that the midinfrared all-fiber QEPAS sensor with a 3D-printed ADM had excellent system stability when compared with the QEPAS system employing separated optical elements, which had an optimum integration time of $70 \mathrm{~s}$ [84]. 


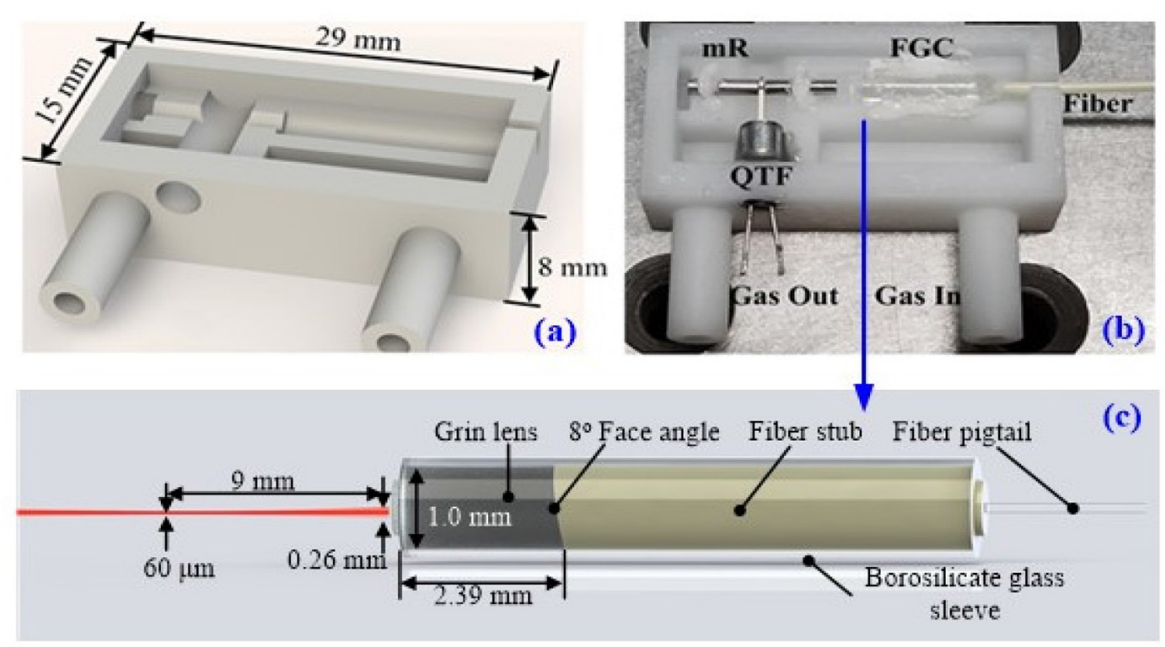

FIGURE 3 | (a) Design model of the 3D-printed ADM. (b) Assembled configuration of a CO-QEPAS sensor with a mid-infrared all-fiber structure and a 3D-printed AMD. (c) Schematic of the fiber-coupled Grin collimator. Reprinted with permission from [82, 83] ๑ The Optical Society.
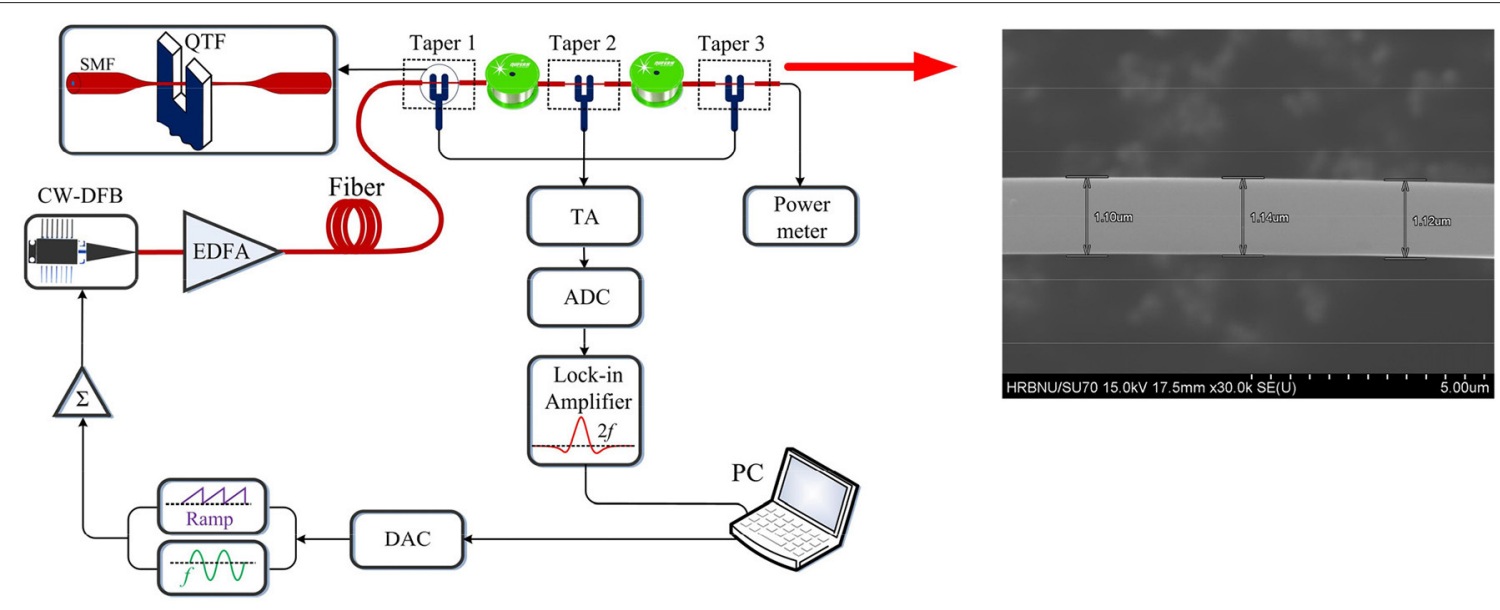

FIGURE 4 | Experimental setup of a FEW-QEPAS sensor. The insert is scanning an electron microscope (SEM) image of fiber taper. Reproduced from [86], with the permission of AIP Publishing.

\section{Long Distance, Distributed Gas Sensing Based on Fiber Evanescent Wave QEPAS}

Most QEPAS based gas sensors are designed for single point concentration measurements, which limits practical applications. An optical fiber gas sensor has the merits of immunity to electromagnetic interruptions, on-line measurements, a compact structure, and flexible in sensor design [85]. A Fiber evanescent wave (FEW) technique based on tapered fiber for gas sensing is used widely. Ma developed a new FEW-QEPAS sensor in 2017, in which the FEW and QEPAS technologies were combined [86], enable a more distributed gas sensing ability. An experimental setup is shown in Figure 4 below.
A $3 \mathrm{~km}$ single mode fiber (Corning SMF-28e ${ }^{+}$) with 3 tapers (Taper 1, Taper 2, and Taper 3) was used in this FEWQEPAS sensor. Three QTFs were used to detect the acoustic wave generated from the three tapers. Evanescent wave power increased when the diameter of the taper decreased. In this investigation, the fabricated tapers had diameters of 1.67, 1.77, and $1.12 \mu \mathrm{m}$, respectively, for Taper 1, Taper 2, and Taper 3. The scanning electron microscope (SEM) image of the fabricated fiber taper is shown in Figure 4. Acetylene $\left(\mathrm{C}_{2} \mathrm{H}_{2}\right)$ was selected as the analyte and a diode laser with an emission wavelength of $1.53 \mu \mathrm{m}$ was used as the excitation source. The MDL of the three tapers was 30,51, 13 ppm, respectively. The detection capability of such a FEW-QEPAS sensor can be further improved by adopting a 
better quality fiber taper with a smaller diameter, a laser source with higher output power, and microresonators.

Compared with the traditional QEPAS system, the new FEW-QEPAS can reduce the sensor volume and improve the stability of the optical system, which is beneficial in applications with limited space or that are sensitive to vibrations. Compared with a FEW gas sensor, the FEW-QEPAS has a better detection performance with a lower MDL. FEW-QEPAS does not need an expensive spectrometer as used in traditional FEW gas sensors. In particular, due to the advantages of low transmission loss and convenient treatment of fibers, FEWQEPAS has the potential of a long distance and a distributed gas sensing ability.

\section{QEPAS Based on Custom QTF With Octupole Electrode Pattern}

A great deal of effort has put into improving QEPAS sensor detection sensitivity, a key element of QTF. Commercially available QTFs with a resonant frequency of $\sim 30 \mathrm{kHz}$ are widely adopted. The electrode layout of widely used QTFs is a quadrupole pattern, which matches the charge distribution produced by the in-plane flexure vibration mode [87]. The adoption of custom QTFs in the QEPAS sensor has been reported since 2013 [88]. Custom QTFs are designed to operate with a fundamental flexural vibration mode with a resonance frequency of a few kilohertz because a low resonance frequency increases the energy accumulation time in a QTF. The equivalent electrical resistance $R$ of QTF represents the loss in the equivalent resistance-inductancecapacitance (RLC) resonator circuit of QTF, which determines the capability of charge generation during the QEPAS sensing process.

Different from the quadrupole pattern, a custom QTF with a novel octupole configuration was developed in 2018 by Spagnolo [89]. The schematic of these two different patterns is shown in Figure 5. Different electrode layouts resulted in different QTF characteristics, such as the resonance frequency, electrical resistance, and quality factor. The electrical resistance was measured for the two QTFs when they were vibrating at the first overtone mode. Compared with the quadrupole pattern $(157.6 \mathrm{k} \Omega)$, the electrical resistance for the octupole contact pattern was strongly reduced $(36.1 \mathrm{k} \Omega$ ), indicating that this configuration had a stronger capability of charge generation. The advantage of the octupole pattern was verified by a QEPAS sensor with water vapor as the target gas sample. The measured signal value for a QEPAS sensor using a QTF with an octupole pattern is $\sim 2.3$ times higher than that obtained by using a QTF with quadrupole pattern at the overtone mode, demonstrating the superiority of an octupole pattern.

\section{In-Plane QEPAS (IP-QEPAS) Sensor}

In producing an effective QTF signal in a QEPAS sensor, the laser beam should pass through the gap between the two prongs of QTF. In the traditional QEPAS sensor, shown in Figure 6A, the laser beam is perpendicular to the QTF plane. This type is called "perpendicular plane-QEPAS," abbreviated as "PP-QEPAS”

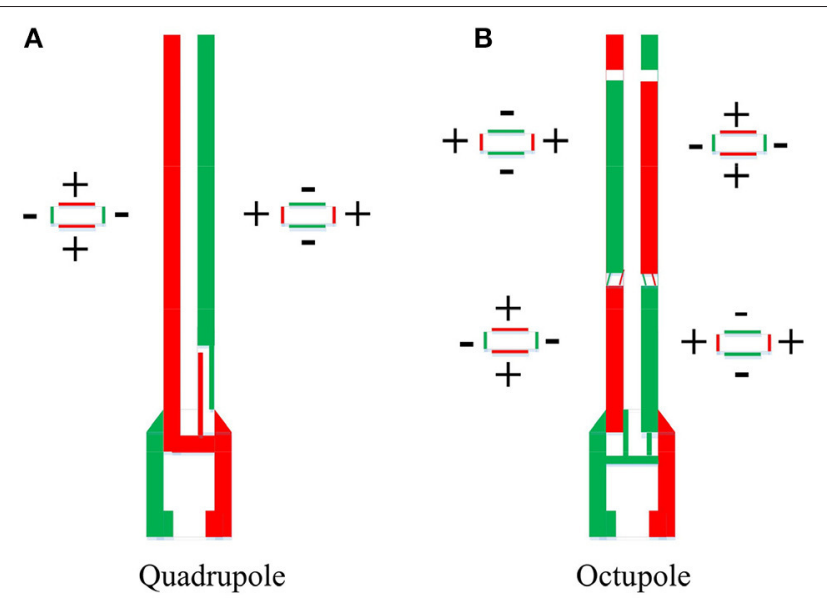

FIGURE 5 | Schematic of two different electrode pattern configuration. (A) Quadrupole pattern. (B) Octupole pattern. Reprinted with permission from [89] (C) The Optical Society.

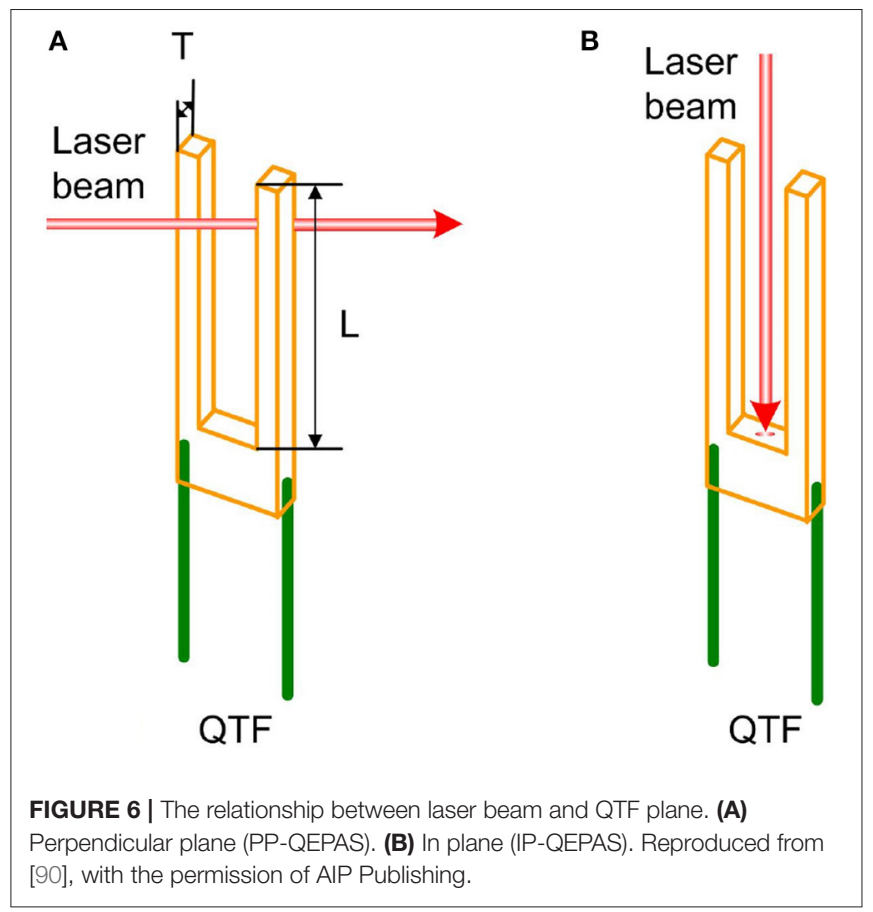

[91, 92]. In PP-QEPAS, the effective acting area for the QTF and acoustic wave is limited by the thickness $(T)$ of the QTF prongs. However, chemical etching of a quartz crystal with a $T$ $>1 \mathrm{~mm}$ cannot ensure sharp edge profiles. Therefore, usually, the $T$ is thin and is in the order of a micrometer (for standard QTF, $T \sim 360 \mu \mathrm{m}$ ), which is disadvantageous for the interaction between an acoustic wave and a QTF and limits the QEPAS sensor performance.

According to the Euler-Bernoulli theoretical model, the resonance frequency of a QTF is related to the QTF's geometric parameters [36]. To reduce resonance frequency, a large length 


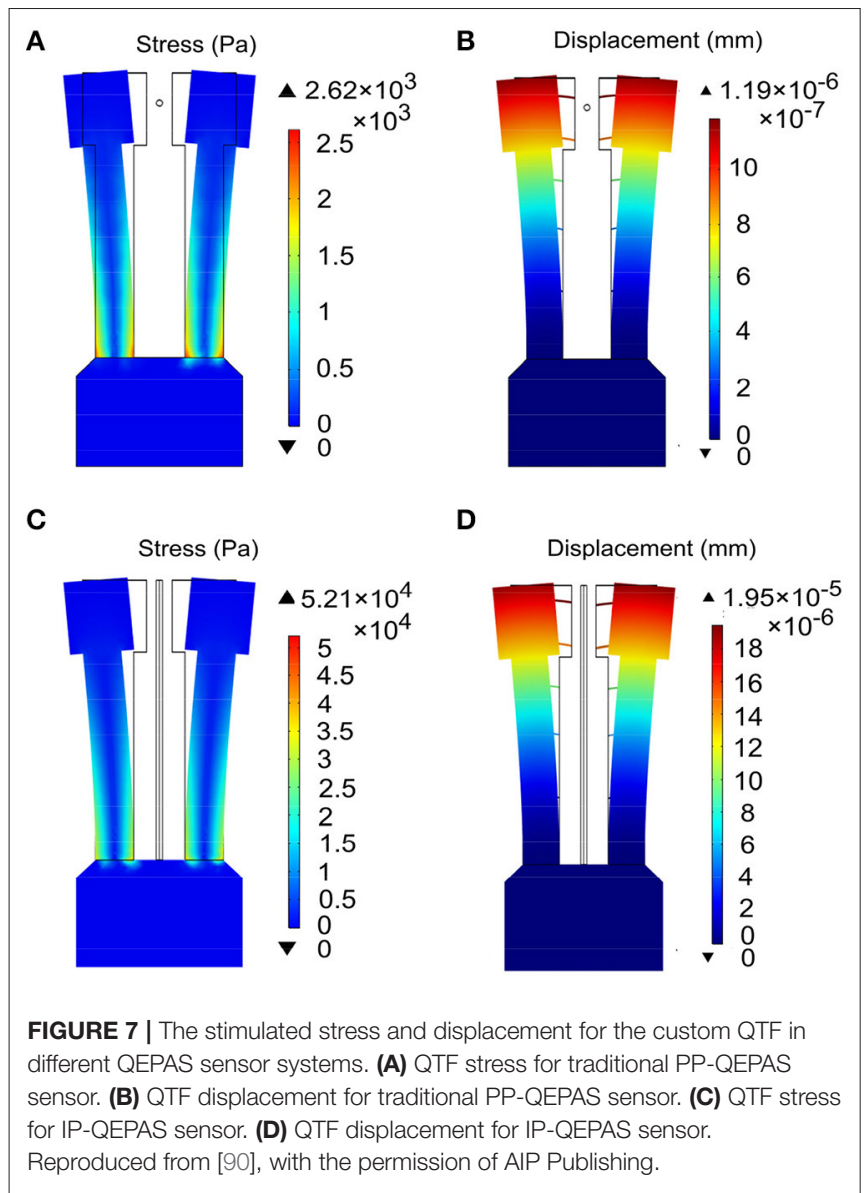

$(L)$ of QTF prongs in a millimeter scale is employed (for standard QTF, $L \sim 3.6 \mathrm{~mm}$ ), which is much larger than $T$. In 2020 , an "in plane quartz-enhanced photoacoustic spectroscopy (IPQEPAS)" was invented [90], in which the laser beam is in the QTF plane to increase the interaction area between acoustic wave and the QTF and hence to improve the sensor performance. The schematic of IP-QEPAS is depicted in Figure 6B. A custom T-shaped QTF with an $L$ of $9.4 \mathrm{~mm}$ and a $T$ of $250 \mu \mathrm{m}$ was designed and used in the experiments to verify this IP-QEPAS technique. Finite element modeling was used to simulate the stress and displacement fields of the custom QTF in IP-QEPAS and traditional PP-PQEAS sensors to support the analyses. The simulated results are shown in Figure 7. It can be seen that the maximum stress and displacement for PP-QEPAS sensor were $2.62 \times 10^{3} \mathrm{~Pa}$ and $1.19 \times 10^{-6} \mathrm{~mm}$, respectively. The corresponding values for the IP-QEPAS sensor were $5.21 \times 10^{4}$ $\mathrm{Pa}$ and $1.95 \times 10^{-5} \mathrm{~mm}$, respectively, which is at least one order of magnitude better than the traditional PP-QEPAS sensor. Water vapor was chosen as the target analyte in the experimental section to perform the verification. The $2 f$ signal amplitude for the IP-QEPAS sensor was $132.88 \mu \mathrm{V}$, which represents a 42.6 times signal improvement compared to the traditional PPQEPAS sensor indicating the superior performance of the IPQEPAS technique.

\section{QUARTZ-ENHANCED PHOTOTHERMAL SPECTROSCOPY (QEPTS) BASED GAS SENSING}

QEPAS is a contact measurement technique, in which a QTF should be embedded in the gas sample [93, 94]. This feature limits its application in many fields, such as combustion diagnostics, long distance measurement, and remote sensing. Furthermore, if the target gas is acidic or corrosive, the silver film coated on the surface of QTF acting as electrodes would be corroded, which will cause a drift of resonance frequency, a decrease of the quality factor, and can even make the QTF fail to operate.

In 2018, a new technique of quartz-enhanced photothermal spectroscopy (QEPTS) was invented by Ma [95]. The QEPTS sensor contains four parts: (a) a QTF is used to receive the light, which is partly transmitted, reflected, and absorbed by the QTF; (b) thermoplastic expansion of QTF appeared when the photothermal energy generated from light absorption is transformed into mechanical motion of the QTF due to the photo-thermo-elastic conversion; (c) QTF enhances this mechanical motion because of its resonant characteristic; (d) due to the essential feature of the piezoelectric effect the QTF converts the mechanical motion into an electrical signal $[96,97]$. QEPTS is based on the photothermal effect or light-thermo-elastic effect and is also called light-induced thermoelastic spectroscopy (LITES) [98]. The principle of QEPTS is shown in Figure 8. In QEPTS, a QTF can be placed far from the target gas and be sealed in a gas chamber with an inert gas such as nitrogen to avoid corrosion, which is different from QEPAS. Therefore, QEPTS is a non-contact measurement method and can be used for remote and standoff gas detection.

\section{The First QEPTS Based Gas Sensor}

The experimental setup of the first QEPTS based gas sensor is shown in Figure 9 [95]. $\mathrm{C}_{2} \mathrm{H}_{2}$ was selected as the analyte, and a diode laser with an emission wavelength of $1.53 \mu \mathrm{m}$ was used as the excitation source. $\mathrm{C}_{2} \mathrm{H}_{2}$ was flushed into an absorption cell with a length of $20 \mathrm{~cm}$. After passing through the cell the diode laser beam was focused onto the surface of a QTF, which had a resonance frequency of $30.72 \mathrm{kHz}$. The background noise of this QEPTS sensor was measured when pure nitrogen was flushed into the absorption cell. Based on the measured signal and noise levels an MDL of $718 \mathrm{ppb}$ for this $\mathrm{C}_{2} \mathrm{H}_{2}$-QEPTS sensor was obtained at the integration time of a lock-in amplifier of $1 \mathrm{~s}$. The corresponding calculated normalized noise equivalent absorption coefficient (NNEA) was $7.63 \times 10^{-9} \mathrm{~cm}^{-1} \mathrm{~W} / \sqrt{ } \mathrm{Hz}$, which is much better than the $3.54 \times 10^{-8} \mathrm{~cm}^{-1} \mathrm{~W} / \sqrt{ } \mathrm{Hz}$ used for a recently reported QEPAS based $\mathrm{C}_{2} \mathrm{H}_{2}$ gas detection study [67].

A finite element model was used to simulate the temperature and displacement fields of the QTF used in the QEPTS sensor to support experiment results. The simulated $2 \mathrm{D}$ and $3 \mathrm{D}$ results are depicted in Figure 10, in which $\Delta \mathrm{Y}$ represents the distance between the laser beam and the top of the QTF prongs. It can be seen that the incident position of the laser beam on the QTF has an impact on the signal level of such a QEPTS sensor. The QTF in the QEPTS sensor was excited, complying with the anti-phase 


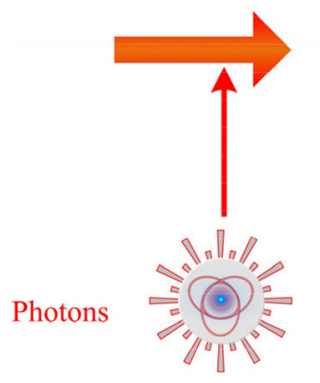

Modulated laser

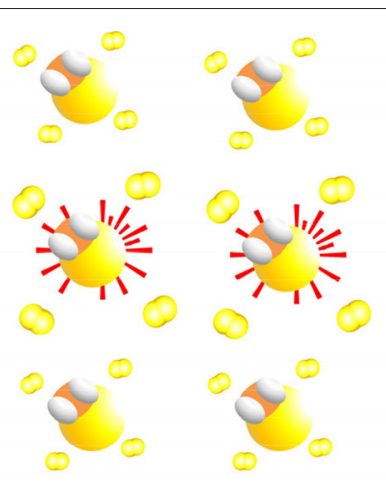

Gas molecule

Absorption

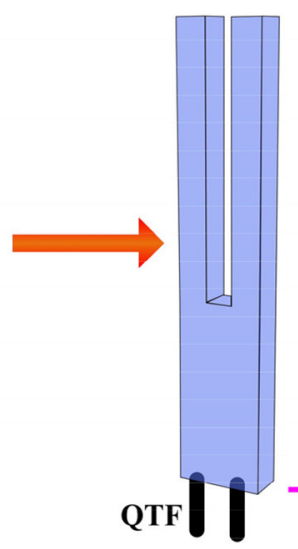

Photothermal detection
Electrical processing

FIGURE 8 | The principle of quartz-enhanced photothermal spectroscopy (QEPTS).

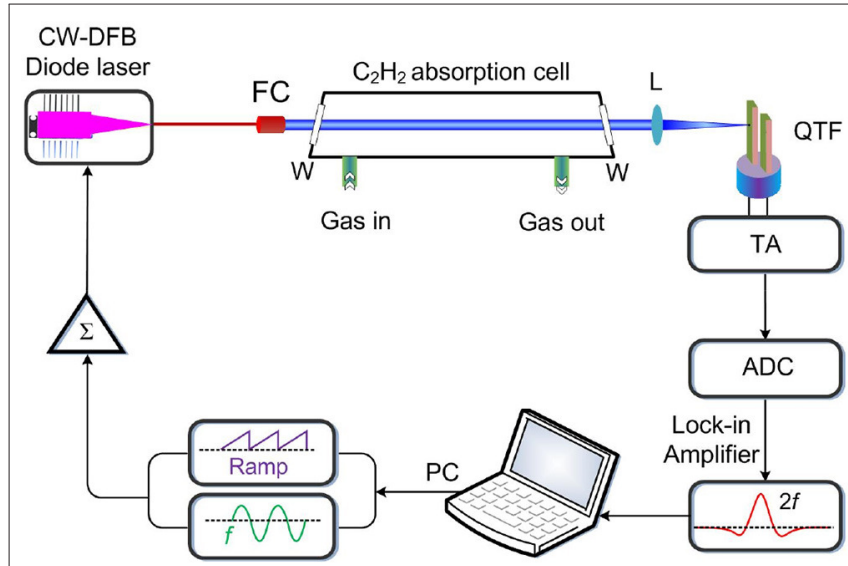

FIGURE 9 | The schematic of the QEPTS sensor. Reprinted with permission from [95] (c) The Optical Society.

mode based on the simulation displayed in Figure 10, which indicates that the two prongs of the QTF vibrate symmetrically (opposite in phase).

\section{QEPTS Sensor Based on a Multipass Cell and a High Quality Factor QTF}

A multipass cell and a high quality factor QTF based QEPTS sensor was demonstrated in 2019, which aimed to improve the detection performance of a QEPTS sensor [99]. The schematic of such a QEPTS sensor system is shown in Figure 11. A Herriot multipass cell with a long optical pathlength of $10.1 \mathrm{~m}$ was used as an absorption cell. A resonant QTF with an increased high quality factor was used to improve the photothermal detection capability, which was sealed in a gas chamber with a low pressure of 20 Torr to minimize the energy loss. The measured quality factor was 50,177 at a pressure of 20 Torr, which represents a 3.4 times increase compared to standard atmospheric pressure. The output laser beam from the multipass cell was focused on the surface of the QTF. In this investigation, CO was selected as the analyte and a diode laser with an emission wavelength of $2.23 \mu \mathrm{m}$ was used as the excitation source.

A finite element model was used to simulate the optimization position of the laser focal point on the surface of the QTF. A normalized integration was performed for the photothermal effect induced by a two prong mechanical displacement of the QTF's surface. As shown in Figure 12, the optimized focal point was located at the root of the QTF's prongs at which the strongest piezoelectric signal amplitude in QEPTS could be obtained.

Figure 12 The normalized integration for photothermal effect induced two prongs mechanical displacement of the QTF's surface. Reprinted with permission from [99] (C) The Optical Society.

\section{QEPTS Sensor Based on a Custom QTF With Enhanced Absorption}

The signal level of the QEPTS sensor is related to the absorbed laser energy by the QTF. However, the high reflection feature of the silver film coated on the surface of QTF minimizes laser absorption. Furthermore, the signal amplitude of QEPTS is inversely proportional to the resonant frequency of the QTF because a QTF with a lower resonant frequency will produce a longer energy accumulation time. Commercially available QTFs with a high resonant frequency of $>30 \mathrm{kHz}$ (such as 30.72 and $32.768 \mathrm{kHz}$ ) are usually adopted in QEPTS sensors [9599]. In QEPTS, the optimum laser incident position on the surface of the QTF surface is located at the root of the prongs at which area the highest signal level could be obtained [99]. In 2020 an ultra-high sensitive QEPTS gas sensor based on a custom QTF with a special coating design to enhance the laser absorption was demonstrated [100]. The area for the optimum 

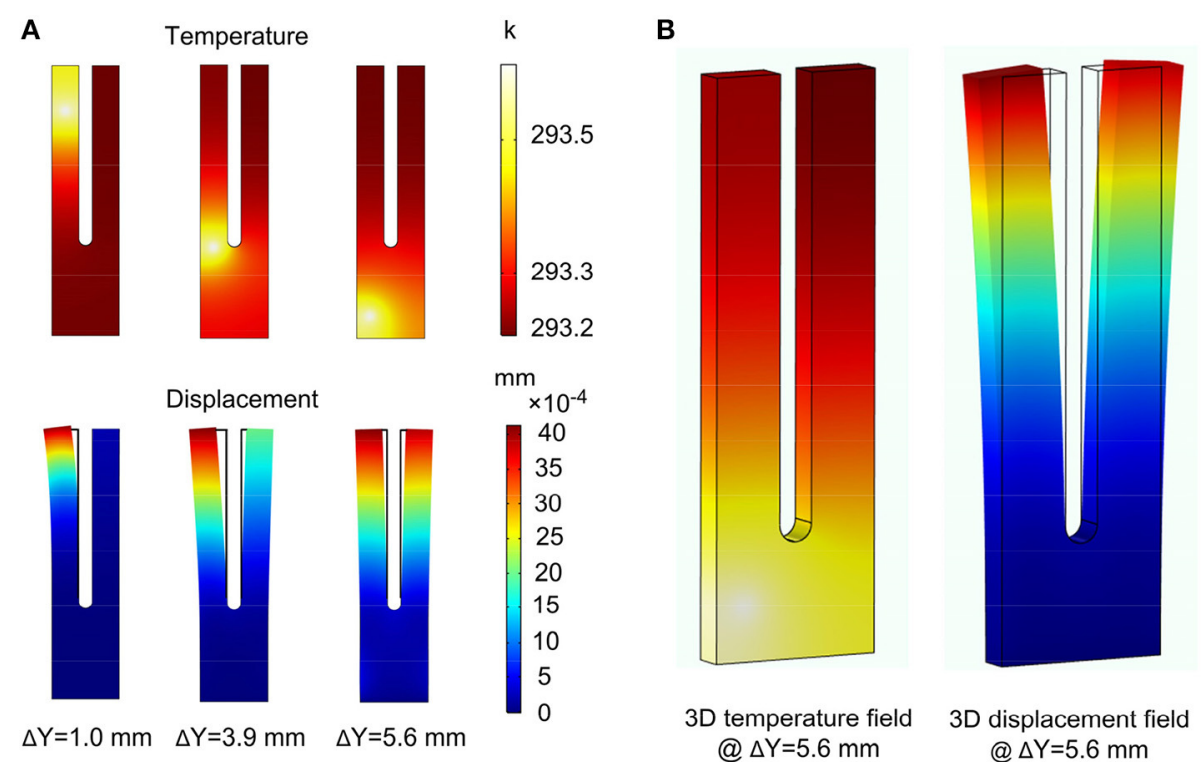

FIGURE 10 | Calculated temperature and displacement fields of the QTF in a QEPTS sensor. (A) Two-dimensional (2D) temperature and displacement fields at different $\Delta Y$. (B) Three-dimensional (3D) temperature and displacement fields at $\Delta Y$ of $5.6 \mathrm{~mm}$. Reprinted with permission from [95] ( ) The Optical Society.

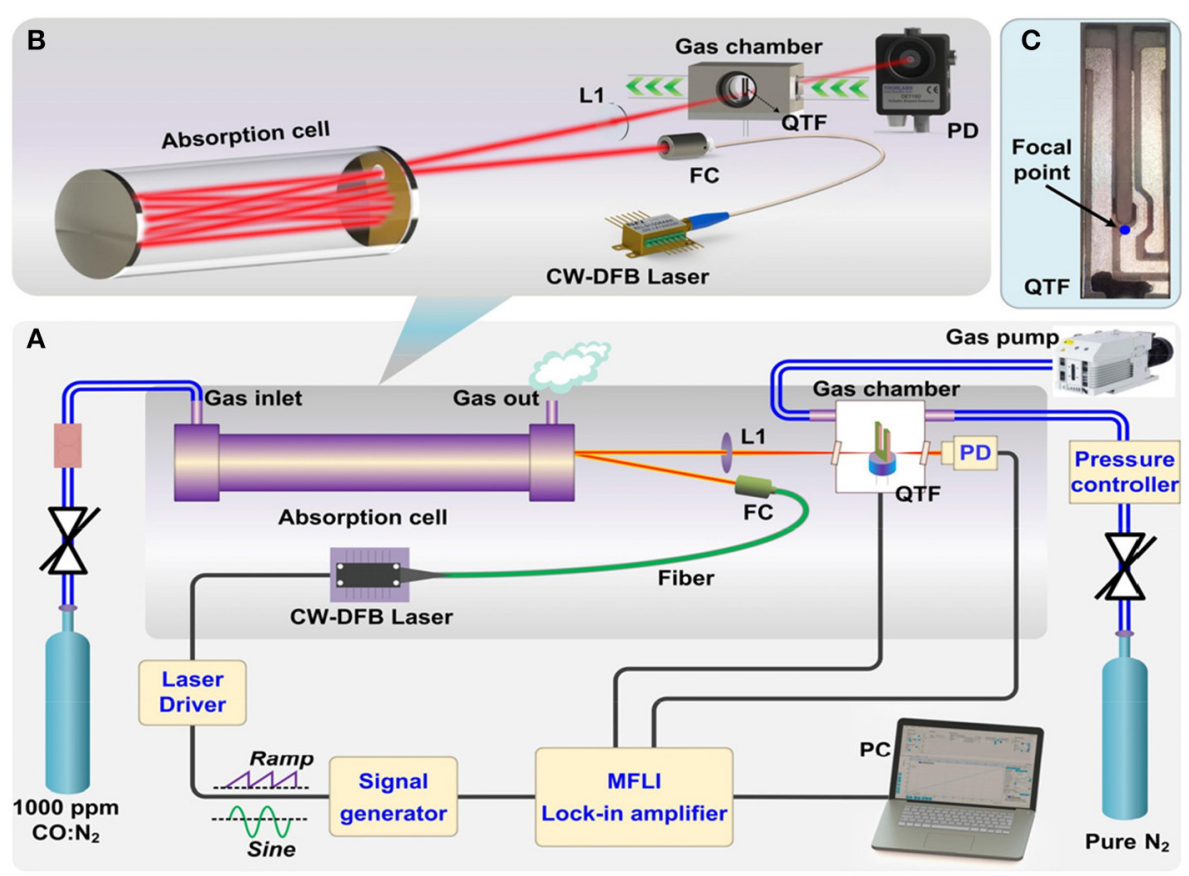

FIGURE 11 | (A) Schematic of a QEPTS sensor system. (B) The particular optical path structure. (C) The image of the used QTF. Reprinted with permission from [99] (C) The Optical Society.

laser incident position on the custom QTF's surface had no metal film coating on one side and improved the laser absorption. On the other side of QTF's surface, the coated gold film reflected the transmitted laser beam and hence further enhanced the absorption. The coating design of the custom QTF and laser beam transmission is shown in Figure 13. Furthermore, the low resonant frequency of $9.35 \mathrm{kHz}$ of the custom QTF was beneficial in improving the QEPTS signal level. $\mathrm{C}_{2} \mathrm{H}_{2}$ was selected as the analyte and a diode laser with an emission wavelength of $1.53 \mu \mathrm{m}$ was used as the excitation source in 


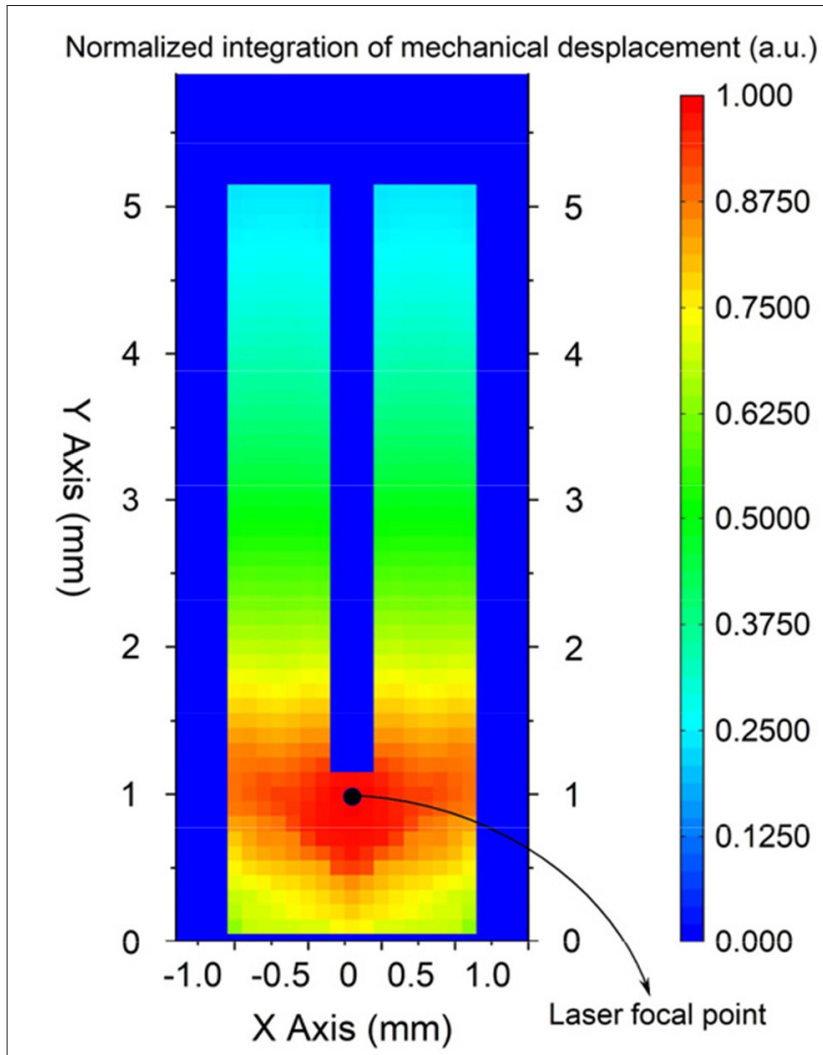

FIGURE 12 | The normalized integration for photothermal effect induced two prongs mechanical displacement of the QTF's surface. Reprinted with permission from [99] ๑ The Optical Society.

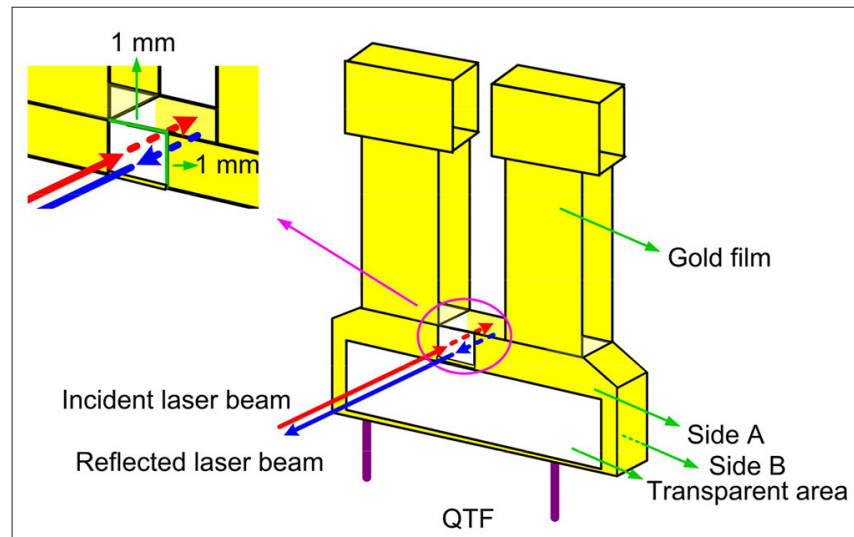

FIGURE 13 | The coating design of a custom QTF and laser beam transmission for the QEPTS sensor. Reproduced from [100], with the permission of AIP Publishing.

the verification experiments. The integration time of lock-in amplifier was1 $\mathrm{s}$.

The noise level for the $\mathrm{C}_{2} \mathrm{H}_{2}$-QEPTS sensor was determined when the $20 \mathrm{~cm}$ long absorption cell was filled with pure nitrogen. As shown in Figure 14, when the optical power was $<2 \mathrm{~mW}$,

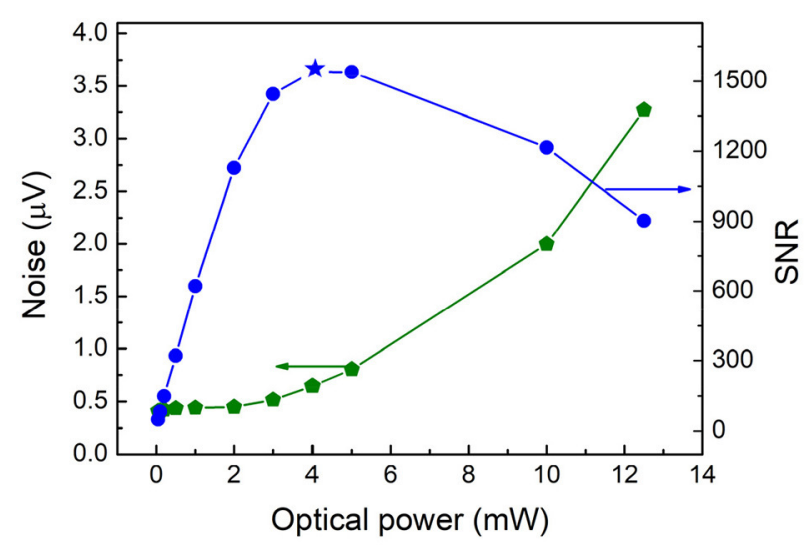

FIGURE $14 \mid \mathrm{C}_{2} \mathrm{H}_{2}$-QEPTS noise level and SNR value as a function of optical power. Reproduced from [100], with the permission of AIP Publishing.

TABLE 1 | The measured performance of QTF based gas sensors.

\begin{tabular}{lccc}
\hline Parameter & QEPAS [67] & $\begin{array}{c}\text { Standard } \\
\text { QTF based } \\
\text { QEPTS [95] }\end{array}$ & $\begin{array}{c}\text { Custom QTF } \\
\text { based } \\
\text { QEPTS }\end{array}$ \\
\hline NNEA $\left(\mathrm{cm}^{-1} \mathrm{~Hz}^{-1 / 2}\right)$ & $3.54 \times 10^{-8}$ & $7.63 \times 10^{-9}$ & $9.16 \times 10^{-10}$ \\
\hline
\end{tabular}

the noise level had an insignificant change with laser power. The noise began to increase with an increase of optical power when it was larger than $2 \mathrm{~mW}$ and it grew faster with a higher power because the fundamental Johnson thermal noise of the QTF became more obvious under this condition. The signal to noise ratio (SNR) was calculated based on the measured $2 f$ signal amplitude and noise level. The obtained SNR value vs. optical power is depicted in Figure 14. It can be seen that the SNR increased with the power initially and then decreased with power. The highest SNR could be achieved when the optical power was $\sim 4 \mathrm{~mW}$.

The corresponding normalized noise equivalent absorption coefficient (NNEA) for this custom QTF based $\mathrm{C}_{2} \mathrm{H}_{2}$-QEPTS was calculated to be $9.16 \times 10^{-10} \mathrm{~cm}^{-1} \mathrm{~W} / \sqrt{ } \mathrm{Hz}$. The comparison of NNEA for the recently reported $\mathrm{C}_{2} \mathrm{H}_{2}$ gas detection sensor using QEPAS and a standard QTF based QEPTS are listed in Table $\mathbf{1 .}$ The QEPTS method showed a distinct advantage over QEPAS and the custom QTF based QEPTS had a better performance than using a standard QTF due to the enhanced laser absorption and low resonant frequency.

\section{Comparison Between QEPAS and QEPTS}

QEPAS and QEPTS were invented in 2002 and 2018, respectively. In QEPAS and QEPTS (also called LITES), a QTF is driven into oscillation through the photoacoustic and photothermal (lightthermo-elastic) effects, respectively. A piezoelectric current is generated in QTF, which is used for retrieving gas concentration. Due to the high quality factor, narrow resonance frequency band, and intrinsic resonance characteristics, QEPAS and QEPTS have the merits of high sensitivity (ppt-ppm level), compact structure, 
TABLE 2 | Performance comparison between QEPAS and QEPTS.

\begin{tabular}{lll}
\hline Parameter & QEPAS & QEPTS \\
\hline MDL (for CO detection) & Good (11.2 ppm) & Better (0.47 ppm) \\
& {$[71]$} & {$[99]$} \\
NNEA (for $\mathrm{C}_{2} \mathrm{H}_{2}$ detection) & Good $(3.54 \times$ & Better $(7.63 \times$ \\
& $10^{-8}$ & $10^{-9} \mathrm{~cm}^{-1}$ \\
& $\left.\mathrm{~cm}^{-1} \mathrm{~W} / \sqrt{ } \mathrm{Hz}\right)[67]$ & $\mathrm{W} / \sqrt{ } \mathrm{Hz})[95]$ \\
Distributed gas sensing ability & Yes $[86]$ & $\mathrm{No}$ \\
Non-contact measurement ability & $\mathrm{No}$ & Yes [95] \\
Corrosion risk of QTF & High & Low
\end{tabular}

low cost, and large dynamic range. However, there are some differences between QEPAS and QEPTS, as indicated in Table 2.

\section{CONCLUSIONS AND FUTURE OUTLOOK}

Due to the merits of a high quality factor $(\sim 100,000$ in vacuum, $\sim 10,000$ at standard atmospheric pressure), a narrow resonance frequency band $(<1 \mathrm{~Hz})$, low cost $(<\$ 1)$, a small volume, and immune to laser wavelength, the QTF is widely used as a sensitive detector in QEPAS and QEPTS based gas sensing. In this invited review paper, recent progress in QTF based QEPAS and QEPTS gas sensing techniques in the past 3 years have been summarized and discussed.

As discussed, a 3D printing technique with the merits of high stability and integration was used to fabricate a compact ADM, which improved the stability of the system and reduced the volume and weight of the QEPAS sensor. An all-fiber configuration has advantages of lower insertion loss, easier optical alignment, improvement in system stability, reduction in sensor size, and a lower cost. Combining with this $3 \mathrm{D}$ printing method, a mid-infrared all-fiber QEPAS sensor was developed to further improve the stability and size of the system. FEW has the merits of on-line measurement and flexible operation. By integrating FEW and QEPAS methods, a long-distance gas sensing technique with distributed gas detection ability was achieved. A commercially available QTF with a resonant frequency $\sim 30 \mathrm{kHz}$ and an electrode layout of a quadrupole pattern is widely used in the QEPAS sensor. A custom QTF with an octupole contact pattern was designed to reduce the electrical resistance, which implied that this configuration had a stronger capability of charge generation. Therefore, the detection sensitivity of a QEPAS sensor-based custom QTF with an octupole contact pattern was improved significantly. Different

\section{REFERENCES}

1. Rousseau R, Loghmari Z, Bahriz M, Bahriz K, Chamassi K, Teissier R, et al. Off-beam QEPAS sensor using an $11-\mu \mathrm{m}$ DFBQCL with an optimized acoustic resonator. Opt Express. (2019) 27:7435-46. doi: 10.1364/OE.27.007435

2. Li G, Dong E, Ji W. A near-infrared trace $\mathrm{CO}_{2}$ detection system based on an $1580 \mathrm{~nm}$ tunable diode laser using a cascaded integrator comb from a traditional PP-QEPAS sensor, in which the laser beam is perpendicular to the QTF plane, an IP-QEPAS sensor with a laser beam in the QTF plane increases the interaction area between acoustic wave and QTF was developed. With over 40 times signal improvement, it has been indicated that the traditional PP-QEPAS sensor has superior capabilities than the IP-QEPAS technique.

QEPAS is a contact measurement technique with limited applications in many fields, including combustion diagnosis, long distance measurement, and remote sensing. If the target gas is acidic or corrosive, the silver film coating the surface of QTF could be corroded, which will cause a drift of the resonance frequency, a decrease of quality factor, and could even make a QTF fail to operate. In 2018, a new technique of quartz-enhanced photothermal spectroscopy (QEPTS), based on the photothermal effect was invented. In QEPTS, a QTF can be placed far from the target gas to avoid corrosion. Different from QEPAS, QEPTS is a non-contact measurement technique that can be used for remote and standoff gas detection. In terms of detection ability, QEPTS showed a distinct superiority of more than one order of improvement in the NNEA when compared with a QEPAS sensor under the same conditions. Further improvement of the QEPTS sensor performance was also achieved when a multipass cell and a custom QTF with enhanced laser absorption and a low resonant frequency were used.

Since the signal level of a QEPAS sensor has a positive correlation with the power of the excitation source, further improvement of detection sensitivity can be achieved by using an advanced light source, such as a high power mid-infrared solid-state laser or a THz laser [101]. For a QEPTS sensor, a midinfrared all-fiber configuration such as a hollow-core fiber could be used as an absorption cell to improve system stability and detection performance [102].

\section{AUTHOR CONTRIBUTIONS}

YM was responsible for this manuscript.

\section{FUNDING}

This work was supported by the National Natural Science Foundation of China (Grant No. 61875047 and 61505041), Natural Science Foundation of Heilongjiang Province of China (Grant No. YQ2019F006), Fundamental Research Funds for the Central Universities, and a Financial Grant from the Heilongjiang Province Postdoctoral Foundation (Grant No. LBH-Q18052). 
21st century. Science. (2009) 326:123-5. doi: 10.1126/science.11 76985

5. Bradshaw JL, Bruno JD, Lascola KM, Leavitt RP, Pham JT, Towner FJ, et al. Small low-power consumption CO-sensor for post-fire cleanup aboard spacecraft. Proc SPIE. (2011) 80320D. doi: 10.1117/12.887517

6. Tao L, Sun K, Khan MA, Miller DJ, Zondlo MA. Compact and portable open-path sensor for simultaneous measurements of atmospheric $\mathrm{N}_{2} \mathrm{O}$ and CO using a quantum cascade laser. Opt Express. (2012) 20:2810618. doi: 10.1364/OE.20.028106

7. Ren W, Farooq A, Davidson DF, Hanson RK. CO concentration and temperature sensor for combustion gases using quantumcascade laser absorption near $4.7 \mu \mathrm{m}$. Appl Phys B. (2012) 107:849-60. doi: 10.1007/s00340-012-5046-1

8. He Y, Ma YF, Tong Y, Yu X, Tittel FK. A portable gas sensor for sensitive CO detection based on quartz-enhanced photoacoustic spectroscopy. Opt Laser Technol. (2019) 115:129-33. doi: 10.1016/j.optlastec.2019.02.030

9. Wang B, Lu H, Chen C, Chen L, Lian H, Dai T, et al. Near-infrared $\mathrm{C}_{2} \mathrm{H}_{2}$ detection system based on single optical path time division multiplexing differential modulation technique and multi-reflection chamber. Appl Sci. (2019) 9:2637. doi: 10.3390/app9132637

10. Ren W, Luo LQ, Tittel FK. Sensitive detection of formaldehyde using an interband cascade laser near $3.6 \mu \mathrm{m}$. Sens Actuators B. (2015) 221:10628. doi: 10.1016/j.snb.2015.07.078

11. He QX, Zheng CT, Liu HF, Li B, Wang YD, Tittel FK. A nearinfrared acetylene detection system based on a $1.534 \mu \mathrm{m}$ tunable diode laser and a miniature gas chamber. Infrared Phys Techn. (2016) 75:939. doi: 10.1016/j.infrared.2016.01.006

12. Sun HY, Ma YF, He Y, Qiao SD, Yang XT, Tittel FK. Highly sensitive acetylene detection based on a compact multi-pass gas cell and optimized wavelength modulation technique. Infrared Phys Techn. (2019) 102:103012. doi: 10.1016/j.infrared.2019.103012

13. Liu K, Wang L, Tan T, Wang GS, Zang WJ, Chen WD, et al. Highly sensitive detection of methane by near-infrared laser absorption spectroscopy using a compact dense-pattern multipass cell. Sens Actuators B. (2015) 220:10005. doi: 10.1016/j.snb.2015.05.136

14. Du Z, Zhang S, Li J, Gao N, Tong K. Mid-infrared tunable laser-based broadband fingerprint absorption spectroscopy for trace gas sensing: a review. Appl Sci. (2019) 9:338. doi: 10.3390/app9020338

15. Wang $\mathrm{Z}, \mathrm{Fu} \mathrm{P}$, Chao $\mathrm{X}$. Laser absorption sensing systems: challenges, modeling, and design optimization. Appl Sci. (2019) 9:2723. doi: 10.3390/app9132723

16. Qiao SD, Qu YC, Ma YF, He Y, Wang Y, Hu YQ, et al. A sensitive carbon dioxide sensor based on photoacoustic spectroscopy with a fixed wavelength quantum cascade laser. Sensors. (2019) 19:4187. doi: 10.3390/s19194187

17. Qiao SD, Ma YF, He Y, Yu X, Zhang ZH, Tittel FK. A sensitive carbon monoxide sensor based on photoacoustic spectroscopy with a $2.3 \mu \mathrm{m}$ midinfrared high-power laser and enhanced gas absorption. Sensors. (2019) 19:3202. doi: 10.3390/s19143202

18. Ma YF, Qiao SD, He Y, Li Y, Zhang ZH, Yu X, et al. Highly sensitive acetylene detection based on multi-pass retro-reflection-cavity-enhanced photoacoustic spectroscopy and a fiber amplified diode laser. Opt Express. (2019) 27:14163-72. doi: 10.1364/OE.27.014163

19. Krzempek K, Dudzik G, Abramski K. Photothermal spectroscopy of $\mathrm{CO}_{2}$ in an intracavity mode-locked fiber laser configuration. Opt Express. (2018) 26:28861-71. doi: 10.1364/OE.26.028861

20. Pietro P, Gaetano S, Frank KT, Spagnolo V. Quartz-enhanced photoacoustic spectroscopy: a review. Sensors. (2014) 14:6165206. doi: $10.3390 / \mathrm{s} 140406165$

21. Eliyahu D, Gileadi E, Galun E, Eliaz N. Atomic force microscope-based meniscus-confined three-dimensional electrodeposition. Adv Mater Technol. (2020) 5:1900827. doi: 10.1002/admt.201900827

22. Barbic M, Eliason L, Ranshaw J. Femto-Newton force sensitivity quartz tuning fork sensor. Sens Actuators A. (2007) 136:5646. doi: 10.1016/j.sna.2007.01.001

23. Paetzold UW, Lehnen S, Bittkau K, Rau U, Carius R. Nanoscale observation of waveguide modes enhancing the efficiency of solar cells. Nano Lett. (2014) 14:6599-605. doi: 10.1021/nl503249n
24. Jahng J, Kwon H, Lee ES. Photo-induced force microscopy by using quartz tuning-fork sensor. Sensors. (2019) 19:1530. doi: 10.3390/s19071530

25. Giessibl FJ. High-speed force sensor for force microscopy and profilometry utilizing a quartz tuning fork. Appl Phys Lett. (1998) 73:3956-8. doi: 10.1063/1.122948

26. Grober RD, Asimovic J, Schuck J, Hessman D, Kindlemann PJ, Hespanha J, et al. Fundamental limits to force detection using quartz tuning forks. Rev Sci Instrum. (2000) 71:2776. doi: 10.1063/1.1150691

27. Zheng HD, Dong L, Ma Y, Wu HP, Liu XL, Yin XK, et al. Scattered light modulation cancellation method for sub-ppb-level $\mathrm{NO}_{2}$ detection in a LD-excited QEPAS system. Opt Express. (2016) 24:A752-61. doi: 10.1364/OE.24.00A752

28. Ma YF, Yu G, Zhang JB, Yu X, Sun R, Tittel FK. Quartz enhanced photoacoustic spectroscopy based trace gas sensors using different quartz tuning forks. Sensors. (2015) 15:7596-604. doi: 10.3390/s150407596

29. Aoust G, Levy R, Raybaut M, Godard A, Melkonian JM, Lefebvre M. Theoretical analysis of a resonant quartz-enhanced photoacoustic spectroscopy sensor. Appl Phys B. (2017) 123:63. doi: $10.1007 / \mathrm{s} 00340-017-6640-\mathrm{z}$

30. Ma YF, Yu G, Zhang JB, Yu X, Sun R. Sensitive detection of carbon monoxide based on QEPAS sensor with a $2.3 \mu \mathrm{m}$ fiber-coupled antimonide diode laser. J Optics. (2015) 17:055401. doi: 10.1088/2040-8978/17/5/055401

31. Zheng HD, Liu YH, Lin HY, Liu B, Gu XH, Li DQ, et al. Quartz-enhanced photoacoustic spectroscopy employing pilot line manufactured custom tuning forks. Photoacoustics. (2020) 17:100158. doi: 10.1016/j.pacs.2019.100158

32. Ma YF, Yu X, Yu G, Li XD, Zhang JB, Chen DY, et al. Multiquartz-enhanced photoacoustic spectroscopy. Appl Phys Lett. (2015) 107:021106. doi: 10.1063/1.4927057

33. Liu K, Guo XY, Yi HM, Chen WD, Zhang WJ, Gao XM. Off-beam quartz-enhanced photoacoustic spectroscopy. Opt Lett. (2009) 34:15946. doi: 10.1364/OL.34.001594

34. Ma YF, He Y, Yu X, Chen C, Sun R, Tittel FK. HCl ppb-level detection based on QEPAS sensor using a low resonance frequency quartz tuning fork. Sens Actuators B. (2016) 233:388-93. doi: 10.1016/j.snb.2016.04.114

35. Ma YF. Review of recent advances in QEPAS-based trace gas sensing. Appl Sci. (2018) 8:1822. doi: 10.3390/app8101822

36. Patimisco P, Borri S, Sampaolo A, Beere HE, Ritchie DA, Vitiello MS, et al. A quartz enhanced photo-acoustic gas sensor based on a custom tuning fork and a terahertz quantum cascade laser. Analyst. (2014) 139:207987. doi: 10.1039/C3AN01219K

37. Ma YF, Lewicki R, Razeghi M, Tittel FK. QEPAS based ppb-level detection of $\mathrm{CO}$ and $\mathrm{N}_{2} \mathrm{O}$ using a high power CW DFB-QCL. Opt Express. (2013) 21:1008-19. doi: 10.1364/OE.21.001008

38. Bell AG. On the production and reproduction of sound by light: the photophone. Am J Sci. (1880) 20:305-24. doi: 10.2475/ajs.s3-20.118.305

39. Borri S, Patimisco P, Galli I, Mazzotti D, Giusfredi G, Akikusa N, et al. Intracavity quartz-enhanced photoacoustic sensor. Appl Phys Lett. (2014) 104:091114. doi: 10.1063/1.4867268

40. Wilcken K, Kauppinen, J. Optimization of a microphone for photoacoustic spectroscopy. Appl Spectrosc. (2003) 57:108792. doi: $10.1366 / 00037020360695946$

41. Moser H, Lendl B. Cantilever-enhanced photoacoustic detection of hydrogen sulfide $\left(\mathrm{H}_{2} \mathrm{~S}\right)$ using NIR telecom laser sources near $1.6 \mu \mathrm{m}$. Appl Phys $B$. (2016) 122:83-98. doi: 10.1007/s00340-016-6355-6

42. Ma YF, He Y, Chen C, Yu X, Zhang JB, Peng JB, et al. Planar laser-based QEPAS trace gas sensor. Sensors. (2016) 16:989. doi: 10.3390/s16070989

43. Elia $\mathrm{A}$, Lugarà $\mathrm{PM}$, Franco $\mathrm{CD}$, Spagnolo V. Photoacoustic techniques for trace gas sensing based on semiconductor laser sources. Sensors. (2009) 9:9616-28. doi: 10.3390/s91209616

44. Kosterev AA, Bakhirkin YA, Curl RF, Tittel FK. Quartzenhanced photoacoustic spectroscopy. Opt Lett. (2002) 27:19024. doi: 10.1364/OL.27.001902

45. Ma YF, He Y, Tong Y, Yu X, Tittel FK. Ppb-level detection of ammonia based on QEPAS using a power amplified laser and a low resonance frequency quartz tuning fork. Opt Express. (2017) 25:2935664. doi: 10.1364/OE.25.029356 
46. Wang Z, Yang M, Fu LY, Chen C, You R, Ren W. Rapid field measurement of ventilation rate using a quartz-enhanced photoacoustic $\mathrm{SF}_{6}$ gas sensor. Meas Sci Technol. (2020) 31:085105. doi: 10.1088/1361-6501/ab8431

47. Yi HM, Maamary R, Gao XM, Sigrist MW, Fertein E, Chen WD. Short-lived species detection of nitrous acid by external-cavity quantum cascade laser based quartz-enhanced photoacoustic absorption spectroscopy. Appl Phys Lett. (2015) 106:101109. doi: 10.1063/1.4914896

48. Safin A, Zweck J, Minkoff SE. A one-way coupled model for the vibration of tuning fork-based trace gas sensors driven by a thermoacoustic wave. Appl Phys B. (2020) 126:29. doi: 10.1007/s00340-020-7376-8

49. Tong Y, Ma YF. Research progress of the trace gas sensing based on quartzenhanced photoacoustic spectroscopy. J Liaocheng Univ. (2019) 32:34-41. doi: 10.19728/j.issn1672-6634.2019.02.005

50. Winkowski M, Stacewicz T. Low noise, open-source QEPAS system with instrumentation amplifier. Sci Rep. (2019) 9:1838. doi: 10.1038/s41598-019-38509-7

51. Kosterev AA, Tittel FK, Serebryakov DV, Malinovsky AL, Morozov IV. Applications of quartz tuning forks in spectroscopic gas sensing. Rev Sci Instrum. (2005) 76:043105. doi: 10.1063/1.1884196

52. Breitegger P, Schweighofer B, Wegleiter H, Knoll M, Lang B, Bergmann A. Towards low-cost QEPAS sensors for nitrogen dioxide detection. Photoacoustics. (2020) 18:100169. doi: 10.1016/j.pacs.2020.100169

53. Wu HP, Dong L, Yin XK, Sampaoloc A, Patimiscoc P, Ma WG, et al. Atmospheric $\mathrm{CH}_{4}$ measurement near a landfill using an ICL-based QEPAS sensor with V-T relaxation self-calibration. Sens Actuators B. (2019) 297:126753. doi: 10.1016/j.snb.2019.126753

54. Xu L, Liu N, Zhou S, Zhang L, Li J. Dual-spectroscopy technique based on quartz crystal tuning fork detector. Sens Actuators A. (2020) 304:111873. doi: 10.1016/j.sna.2020.111873

55. Yang XT, Xiao YH, Ma YF, He Y, Tittel FK. A miniaturized QEPAS trace gas sensor with a 3D-printed ADM. Sensors. (2017) 17:1750. doi: 10.3390/s17081750

56. Mordmueller M, Edelmann S, Knestel M, Schade W, Willer U. Phase optimized photoacoustic sensing of gas mixtures. Appl Sci. (2020) 10:438. doi: 10.3390/app10020438

57. Li Y, Wang RZ, Tittel FK, Ma YF. Sensitive methane detection based on quartz-enhanced photoacoustic spectroscopy with a highpower diode laser and wavelet filtering. Opt Laser Eng. (2020) 132:106155. doi: 10.1016/j.optlaseng.2020.106155

58. Hayden J, Baumgartner B, Lendl B. Anomalous humidity dependence in photoacoustic spectroscopy of CO explained by kinetic cooling. Appl Sci. (2020) 10:843. doi: 10.3390/app10030843

59. Milde T, Hoppe M, Tatenguem H, Mordmüller M, Ogorman J, Willer U, et al. QEPAS sensor for breath analysis: a behavior of pressure. Appl Optics. (2018) 57:C120-7. doi: 10.1364/AO.57.00C120

60. Lewicki R, Kosterev AA, Thomazy DM, Risby TH, Solga S, Schwartz TB, et al. Real time ammonia detection in exhaled human breath using a distributed feedback quantum cascade laser based sensor. Proc SPIE. (2011) 79450K. doi: 10.1117/12.874887

61. Köhring M, Böttger S, Willer U, Schade W. LED-absorption-QEPAS sensor for biogas plants. Sensors. (2015) 15:12092-102. doi: 10.3390/s150512092

62. Pohlkötter A, Köhring M, Willer U, Schade W. Detection of molecular oxygen at low concentrations using quartz enhanced photoacoustic spectroscopy. Sensors. (2010) 10:8466-77. doi: 10.3390/s1009 08466

63. Nguyen BT, Triki M, Desbrosses G, Vicet A. Quartz-enhanced photoacoustic spectroscopy sensor for ethylene detection with a $3.32 \mu \mathrm{m}$ distributed feedback laser diode. Rev Sci Instrum. (2015) 86:023111. doi: 10.1063/1.4913383

64. Zampolli S, Mengali S, Liberatore N, Elmi I, Masini L, Sanmartin M, et al. A MEMS-enabled deployable trace chemical sensor based on fast gaschromatography and quartz enhanced photoacousic spectoscopy. Sensors. (2020) 20:120. doi: 10.3390/s20010120

65. Jahjah M, Belahsene S, Nähle L, Fischer M, Koeth J, Rouillard Y, et al. Quartz enhanced photoacoustic spectroscopy with a $3.38 \mu \mathrm{m}$ antimonide distributed feedback laser. Opt Lett. (2012) 37:2502-4. doi: 10.1364/OL.37.002502
66. Dong L, Spagnolo V, Lewicki R, Tittel FK. Ppb-level detection of nitric oxide using an external cavity quantum cascade laser based QEPAS sensor. Opt Express. (2011) 19:24037-45. doi: 10.1364/OE.19.024037

67. Ma YF, He Y, Zhang LG, Yu X, Zhang JB, Sun R, et al. Ultra-high sensitive acetylene detection using quartz-enhanced photoacoustic spectroscopy with a fiber amplified diode laser and a $30.72 \mathrm{kHz}$ quartz tuning fork. Appl Phys Lett. (2017) 110:031107. doi: 10.1063/1.4974483

68. Ma YF, He Y, Yu X, Zhang JB, Sun R, Tittel FK. Compact all-fiber quartzenhanced photoacoustic spectroscopy sensor with a $30.72 \mathrm{kHz}$ quartz tuning fork and spatially resolved trace gas detection. Appl Phys Lett. (2016) 108:091115. doi: 10.1063/1.4943233

69. Jiang M, Feng QL, Wang CY, Wei YF, Liang TL, Wang XF. Ammonia sensor based on QEPAS with HC-PBF as reference cell. Proc SPIE. (2015) 96200F. doi: 10.1117/12.2192986

70. Triki M, Nguyen BT, Vicet A. Compact sensor for methane detection in the mid infrared region based on quartz enhanced photoacoustic spectroscopy. Infrared Phys Technol. (2015) 69:74-80. doi: 10.1016/j.infrared.2015.01.016

71. Ma YF, Tong Y, He Y, Yu X, Tittel FK. High power DFB diode laser based CO-QEPAS sensor: optimization and performance. Sensors. (2018) 18:122. doi: $10.3390 / \mathrm{s} 18010122$

72. Waclawek JP, Moser H, Lendl B. Compact quantum cascade laser based quartz-enhanced photoacoustic spectroscopy sensor system for detection of carbon disulfide. Opt Express. (2016) 24:6559-71. doi: 10.1364/OE.24.006559

73. Liu K, Zhao WX, Wang L, Tan T, Wang GS, Zhang WJ, et al. Quartzenhanced photoacoustic spectroscopy of HCN from 6433 to $6613 \mathrm{~cm}^{-1}$. Opt Commun. (2015) 340:126-30. doi: 10.1016/j.optcom.2014.12.001

74. Dong L, Lewicki R, Liu K, Buerki PR, Weida MJ, Tittel FK. Ultrasensitive carbon monoxide detection by using EC-QCL based quartzenhanced photoacoustic spectroscopy. Appl Phys B. (2012) 107:27583. doi: $10.1007 /$ s00340-012-4949-1

75. Lassen M, Lamard L, Feng Y, Peremans A, Petersen JC. Off-axis quartz-enhanced photoacoustic spectroscopy using a pulsed nanosecond mid-infrared optical parametric oscillator. Opt Lett. (2016) 41:411821. doi: $10.1364 /$ OL. 41.004118

76. Lewicki R, Wysocki G, Kosterev AA, Tittel FK. QEPAS based detection of broadband absorbing molecules using a widely tunable, cw quantum cascade laser at $8.4 \mu \mathrm{m}$. Opt Express. (2007) 15:7357-66. doi: 10.1364/OE.15.007357

77. Dong L, Kosterev AA, Thomazy D, Tittel FK. Compact portable QEPAS multi-gas sensor. Proc SPIE. (2011) 7945:631-40. doi: 10.1117/12.875108

78. Ren W, Jiang W, Sanchez NP, Patimisco P, Spagnolo V, Zah C, et al. Hydrogen peroxide detection with quartz-enhanced photoacoustic spectroscopy using a distributed-feedback quantum cascade laser. Appl Phys Lett. (2014) 104:041117. doi: 10.1063/1.4863955

79. Bauer C, Willer U, Lewicki R, Pohlkötter A, Kosterev AA, Kosynkin D, et al. A mid-infrared QEPAS sensor device for TATP detection. J Phys. (2009) 157:012002. doi: 10.1088/1742-6596/157/1/012002

80. Hu L, Zheng CT, Zheng J, Wang YD, Tittel FK. Quartz tuning fork embedded off-beam quartz-enhanced photoacoustic spectroscopy. Opt Lett. (2019) 44:2562-5. doi: 10.1364/OL.44.002562

81. Wu HP, Dong L, Zheng HD, Yu YJ, Ma WG, Zhang L, et al. Beat frequency quartz-enhanced photoacoustic spectroscopy for fast and calibration-free continuous trace-gas monitoring. Nat Commun. (2017) 8:15331. doi: 10.1038/ncomms15331

82. He Y, Ma YF, Tong Y, Yu X, Tittel FK. HCN ppt-level detection based on a QEPAS sensor with amplified laser and a miniaturized 3Dprinted photoacoustic detection channel. Opt Express. (2018) 26:966675. doi: 10.1364/OE.26.009666

83. Ma YF, Tong Y, He Y, Jin XG, Tittel FK. Compact and sensitive mid-infrared all-fiber quartz-enhanced photoacoustic spectroscopy sensor for carbon monoxide detection. Opt Express. (2019) 27:9302-12. doi: 10.1364/OE.27.009302

84. Wang Z, Li Z, Ren W. Quartz-enhanced photoacoustic detection of ethylene using a $10.5 \mu \mathrm{m}$ quantum cascade laser. Opt Express. (2016) 24:414354. doi: $10.1364 /$ OE. 24.004143

85. Yu Z, Jin L, Sun L, Li J, Ran Y, Guan BO. Highly sensitive fiber taper interferometric hydrogen sensors. IEEE Photonics J. (2016) 8:1. doi: 10.1109/JPHOT.2015.2507369 
86. He Y, Ma YF, Tong Y, Yu X, Peng ZF, Gao J, et al. Long distance, distributed gas sensing based on micro-nano fiber evanescent wave quartz-enhanced photoacoustic spectroscopy. Appl Phys Lett. (2017) 111:241102. doi: 10.1063/1.5003121

87. Patimisco P, Sampaolo A, Dong L, Tittel FK, Spagnolo V. Recent advances in quartz enhanced photoacoustic sensing. Appl Phys Rev. (2018) 5:011106. doi: 10.1063/1.5013612

88. Borri S, Patimisco P, Sampaolo A, Vitiello MS, Beere HE, Ritchie DA, et al. Terahertz quartz enhanced photo-acoustic sensor. Appl Phys Lett. (2013) 103:021105. doi: 10.1063/1.4812438

89. Patimisco P, Sampaolo A, Giglio M, Mackowiak V, Rossmadl H, Gross $\mathrm{B}$, et al. Octupole electrode pattern for tuning forks vibrating at the first overtone mode in quartz-enhanced photoacoustic spectroscopy. Opt Lett. (2018) 43:1854-7. doi: 10.1364/OL.43.001854

90. Ma YF, Qiao SD, Patimisco P, Sampaolo V, Wang Y, Tittel FK, et al. In plane quartz-enhanced photoacoustic spectroscopy. Appl Phys Lett. (2020) 116:061101. doi: 10.1063/1.5142330

91. Li ZL, Wang Z, Qi Y, Jin W, Ren W. Improved evanescent-wave quartzenhanced photoacoustic CO sensor using an optical fiber taper. Sens Actuators B. (2017) 248:1023-8. doi: 10.1016/j.snb.2017.03.029

92. Ma YF, Tong Y, He Y, Long JH, Yu X. Quartz-enhanced photoacoustic spectroscopy sensor with a small-gap quartz tuning fork. Sensors. (2018) 18:2047. doi: 10.3390/s18072047

93. Duquesnoy M, Aoust G, Melkonian JM, Lévy R, Raybaut M, Godard A. Quartz enhanced photoacoustic spectroscopy based on a custom quartz tuning fork. Sensors. (2019) 19:1362. doi: 10.3390/s19061362

94. Zhang QD, Chang J, Cong ZH, Feng YW, Wang ZL, Wang FP, et al. Pptv-level intra-cavity QEPAS sensor for acetylene detection using a high power Q-switched fiber laser. IEEE Sens J. (2019) 19:61816. doi: 10.1109/JSEN.2019.2910665

95. Ma YF, He Y, Tong Y, Yu X, Tittel FK. Quartz-tuning-fork enhanced photothermal spectroscopy for ultra-high sensitive trace gas detection. Opt Express. (2018) 26:32103-10. doi: 10.1364/OE.26.032103

96. Zhang Q, Chang J, Cong Z, Wang, Z. Quartz tuning fork enhanced photothermal spectroscopy gas detection system with a novel QTF-self-difference technique. Sens. Actuators B. (2019) 209:111629. doi: 10.1016/j.sna.2019.111629

97. Zheng HD, Lin HY, Dong L, Huang Z, Gu XH, Tang JY, et al. Quartzenhanced photothermal-acoustic spectroscopy for trace gas analysis. Appl Sci. (2019) 9:4021. doi: 10.3390/app9194021

98. Hu L, Zheng CT, Zhang Y, Zheng J, Wang YD, Tittel FK. Compact all-fiber light-induced thermoelastic spectroscopy for gas sensing. Opt Lett. (2020) 45:1894-7. doi: 10.1364/OL.388754

99. He Y, Ma YF, Tong Y, Yu X, Tittel FK. Ultra-high sensitive light-induced thermoelastic spectroscopy sensor with a high Q-factor quartz tuning fork and a multipass cell. Opt Lett. (2019) 44:1904-7. doi: 10.1364/OL.44. 001904

100. Ma YF, He Y, Patimisco P, Sampaolo A, Qiao SD, Yu X, et al. Ultrahigh sensitive trace gas detection based on light-induced thermoelastic spectroscopy and a custom quartz tuning fork. Appl Phys Lett. (2020) 116:011103. doi: 10.1063/1.5129014

101. Ma YF, Sun HY, Ran BF, Zhang SC, Zhang H, Tittel FK, et al. Passively Q-switched Tm: $\mathrm{YAlO}_{3}$ laser based on $\mathrm{WS}_{2} / \mathrm{MoS}_{2}$ twodimensional nanosheets at $2 \mu \mathrm{m}$. Opt Laser Technol. (2020) 126:106084. doi: 10.1016/j.optlastec.2020.106084

102. Jaworski P, Krzempek K, Dudzik G, Sazio PJ, Belardi W. Nitrous oxide detection at $5.26 \mu \mathrm{m}$ with a compound glass antiresonant hollow-core optical fiber. Opt Lett. (2020) 45:1326-9. doi: 10.1364/OL. 383861

Conflict of Interest: The author declares that the research was conducted in the absence of any commercial or financial relationships that could be construed as a potential conflict of interest.

Copyright (c) $2020 \mathrm{Ma}$. This is an open-access article distributed under the terms of the Creative Commons Attribution License (CC BY). The use, distribution or reproduction in other forums is permitted, provided the original author $(s)$ and the copyright owner(s) are credited and that the original publication in this journal is cited, in accordance with accepted academic practice. No use, distribution or reproduction is permitted which does not comply with these terms. 